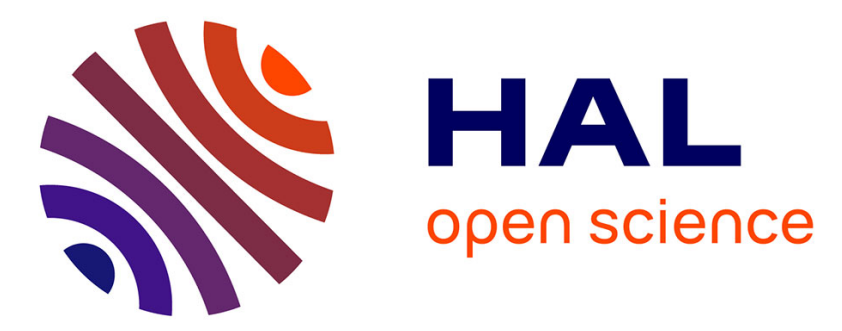

\title{
Leader power and leader self-serving behavior: The role of effective leadership beliefs and performance information
}

\author{
Diana Rus, Daan van Knippenberg, Barbara Wisse
}

\section{- To cite this version:}

Diana Rus, Daan van Knippenberg, Barbara Wisse. Leader power and leader self-serving behavior: The role of effective leadership beliefs and performance information. Journal of Experimental Social Psychology, 2010, 46 (6), pp.922. 10.1016/j.jesp.2010.06.007 . hal-00864368

\section{HAL Id: hal-00864368 https://hal.science/hal-00864368}

Submitted on 21 Sep 2013

HAL is a multi-disciplinary open access archive for the deposit and dissemination of scientific research documents, whether they are published or not. The documents may come from teaching and research institutions in France or abroad, or from public or private research centers.
L'archive ouverte pluridisciplinaire HAL, est destinée au dépôt et à la diffusion de documents scientifiques de niveau recherche, publiés ou non, émanant des établissements d'enseignement et de recherche français ou étrangers, des laboratoires publics ou privés. 


\section{Accepted Manuscript}

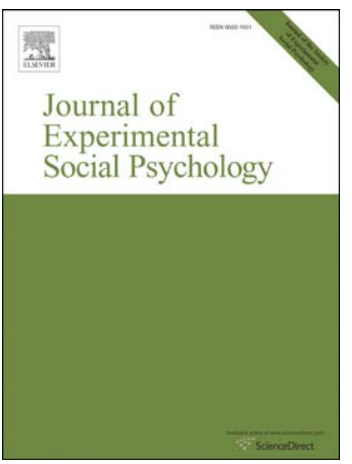

PII:

Leader power and leader self-serving behavior: The role of effective leadership beliefs and performance information

Diana Rus, Daan van Knippenberg, Barbara Wisse

DOI:

S0022-1031(10)00146-0

Reference: $\quad$ YJESP 2489

To appear in: Journal of Experimental Social Psychology

Received date: $\quad 12$ February 2010

Revised date: $\quad 30$ May 2010

Accepted date: 21 June 2010

Please cite this article as: Rus, D., van Knippenberg, D. \& Wisse, B., Leader power and leader self-serving behavior: The role of effective leadership beliefs and performance information, Journal of Experimental Social Psychology (2010), doi: 10.1016/j.jesp.2010.06.007

This is a PDF file of an unedited manuscript that has been accepted for publication. As a service to our customers we are providing this early version of the manuscript. The manuscript will undergo copyediting, typesetting, and review of the resulting proof before it is published in its final form. Please note that during the production process errors may be discovered which could affect the content, and all legal disclaimers that apply to the journal pertain. 
RUNNING HEAD: Leader Self-Serving Behavior

Leader Power and Leader Self-Serving Behavior: The Role of Effective Leadership Beliefs and Performance Information

Diana Rus

University of Groningen

Grote Kruisstraat 2/1

9712 TS Groningen

The Netherlands

Email: d.c.rus@,rug.nl

Daan van Knippenberg

Rotterdam School of Management

Erasmus University Rotterdam

PO Box 1738

3000 DR Rotterdam, The Netherlands

Email: dvanknippenberg@,rsm.nl

\author{
Barbara Wisse \\ University of Groningen \\ Grote Kruisstraat 2/1 \\ 9712 TS Groningen \\ The Netherlands \\ Email: b.m.wisse@,rug.nl
}

Correspondence concerning this article should be addressed to Diana Rus, University of Groningen, Grote Kruisstraat 2/1, 9712 TS Groningen, The Netherlands, Email: d.c.rus@rug.nl 


\begin{abstract}
In this research we investigated the role played by leader power in determining leader self-serving behavior. Based on an integration of insights from research on the determinants of leader behavior and the power-approach theory, we hypothesized that with higher leader power leader self-serving behavior is determined more by internal states like effective leadership beliefs and less by external cues like performance information. We found support for this prediction across two experiments and one organizational survey assessing leader behavior along a self-serving - group-serving continuum. Overall, these results suggest that whether leaders benefit the collective or act selfservingly is not a function of their power per se but rather that leader power determines the extent to which internal belief states or external cues influence leader self versus group-serving behavior.
\end{abstract}

Keywords: power; leadership; self-serving behavior; leadership schemas; performance information 
Leader Power and Leader Self-Serving Behavior: The Role of Effective Leadership Beliefs and Performance Information

Recently the popular media has become replete with headlines decrying top executives' lofty bonuses and profligate spending at a time when taxpayer money was used to protect their companies from insolvency. For example, John Thain, the ousted CEO of Merrill Lynch, spent \$ 1.2 Million on redecorating his office, as the company was firing employees and was on the brink of bankruptcy. Needless to say, this lavish spending of company money at a time when rank and file employees were losing their livelihoods drew the ire of the general public and the body politic. Next to the popular outcry against leaders' blatant misallocation of resources, numerous studies have shown that leaders who distribute resources to their own advantage harm group interests (Aquino \& Reed, 1998) and are less effective than those who prioritize their group's well-being (Choi \& MaiDalton, 1999; De Cremer \& van Knippenberg, 2004). Because self-serving leader behavior can engender a host of negative consequences such as decreased leader effectiveness, public embarrassment, and even organizational collapse, it seems essential to understand why some leaders act self-servingly and fill their own coffers while others act to benefit their groups.

Evidence of leader self-serving behavior is probably nowhere more blatant than in the manner in which leaders distribute scarce resources such as pay increases and bonuses, but also other types of assets such as office space, parking lots, and recognition. Because these resources are limited, the more of the resource the leader allocates to one person (for instance to him or herself), the less is left over for the others. But how do leaders decide upon such resource allocations? Previous research has identified effective leadership beliefs (e.g., Rus, van Knippenberg, \& Wisse, in press) as well as the use of equity rules, such as reliance on performance information (e.g., De Cremer \& van Dijk, 2005, 2008), as being key determinants of leader allocation decisions. However, to date, it remains unclear under what circumstances leaders' self-serving versus group-serving allocations would be primarily informed by effective leadership beliefs or by performance information. 
Based on recent insights derived from the power-approach theory (cf. Keltner, Gruenfeld, \& Anderson, 2003), we propose that power should moderate the extent to which leader self-serving versus group-serving behavior is contingent on effective leadership beliefs or on performance information. Because elevated power seems to render individuals less sensitive to situational constraints and more sensitive to internal cues as compared to low power, higher levels of leader power should be associated with a greater sway of leaders' internal belief states, such as effective leadership beliefs (Lord \& Maher, 1993), on leader behaviors. In contrast, relatively low levels of leader power should be associated with a stronger influence of external cues like performance information (De Cremer \& van Dijk, 2005). On the basis of these contingencies, either higherpower or lower-power leaders may act more self-servingly. By introducing leader power as a predictor of the relative clout of these previously identified influences on leader (self-serving) behavior, and by extending the power-approach theory to power variations within the leader role, the present study makes an important step toward a more integrative understanding of the interplay between power and variables that are particularly relevant to leadership research.

\section{Leader Self-Serving Behavior and Power}

Power, or the asymmetric control over valued resources (Fiske, 1993; French \& Raven, 1959; Keltner et al., 2003), is inherent in the leader role. The leader role places individuals in a position where, next to motivating, coordinating, and directing group members' efforts (De Cremer \& van Knippenberg, 2003; Farmer \& Aquinis, 2005), they have the authority to make decisions that affect individual and group level outcomes. Hence, the leader role entails control over valuable resources, and thus the possession of power. However, while typically leaders have more power than their subordinates, not all leaders will have the same amount of power at their disposal. One reason for these power differentials resides in the fact that organizations tend to give rise to some form of hierarchy, whether by design or via organic processes. As a result of these different gradients of authority some leaders will command more power than others. Usually, the higher a leader is in the 
organizational hierarchy, the more control he/she can exercise over resources (Tannenbaum, 1968). For instance, while some leaders can dismiss or fire employees as they see fit, others need to garner the support of the upper-level echelons to do the same. Likewise, while some leaders can promote subordinates at will, others have to pay heed to strict guidelines and regulations.

The power-approach theory (Keltner et al., 2003) suggests that power has wide-ranging psychological and behavioral consequences by fundamentally transforming the way individuals perceive the world, others, and themselves. To this end, recent findings suggest that the powerful are attuned to different types of information than lower power individuals (Bargh, Raymond, Pryor, \& Strack, 1995; Chen, Lee-Chai, \& Bargh, 2001; Galinsky, Magee, Gruenfeld, Whitson, \& Liljenquist, 2008). Indeed, elevated power seems to increase behavioral sensitivity to information deriving from internal (temporary and chronic) states, and to simultaneously decrease behavioral sensitivity to information stemming from the situational context.

First, the powerful, in contrast to their low power counterparts, seem to behave more in line with internal (temporary and chronic) preferences, feelings, and beliefs (Keltner et al., 2003). For instance, Chen and colleagues (2001) found that power-primed communally-oriented participants acted more selflessly and power-primed exchange-oriented participants acted more selfishly than participants exposed to neutral primes. Similarly, Bargh et al. (1995) showed that activating the concept of power in men who had a predisposition towards sexual harassment automatically triggered sex-related concepts and led them to view female discussion partners as sexual objects. More recently, Galinsky and colleagues (2008) found that high power participants' social value orientations were better predictors of their negotiation behaviors than their partners' reputations.

Second, high power individuals may react to a lesser extent to social norms, others' evaluations, and contextual cues than low power individuals. For instance, powerful individuals seem to act more at will (Galinsky, Gruenfeld, \& Magee, 2003; Magee, Galinsky, \& Gruenfeld, 2007), to engage in more goal-directed behavior (Anderson, Keltner, \& John, 2003; Chen et al., 
2001; Guinote, 2007a, 2007b), and to act in more variable ways (Guinote, Judd, \& Brauer, 2002) than their low power counterparts. The powerful also appear to be less concerned with how others see them or judge their actions (Galinsky et al., 2008), to be poor assessors of others' perspectives and emotions (Galinsky, Magee, Inesi, \& Gruenfeld, 2006), to respond less to others' emotional displays (van Kleef, De Dreu, Pietroni, \& Manstead, 2006), and to be less likely to fall prey to influence attempts than the powerless (Anderson \& Berdahl, 2002; Berdahl \& Martorana, 2006; Galinsky et al., 2008). In sum, both theory as well as existing empirical evidence suggests that power opens up the door to influence from internal, chronic sources of information, and closes the door to influence from more situational, context-dependent sources of information.

Whereas previous studies have identified both effective leadership beliefs (i.e., internalized beliefs about how a leader should behave in order to be effective) as well as equity rules (i.e., performance information) as predicting self versus group-serving leader behavior (De Cremer \& van Dijk, 2005, 2008; Rus et al., in press), they have provided little clarity as to the conditions under which leaders would rely on their beliefs or on performance information. Based on the aforementioned insights derived from the power-approach theory, we propose that power variations within the leader role should inform leaders' relative receptiveness to these internal (i.e., effective leadership beliefs) and external (i.e., performance information) informational cues when making resource allocations. Specifically, high power leaders, in contrast to low power leaders, should be more open to the influence of internal belief states, and hence more open to the influence of effective leadership beliefs. Also, high power leaders, in contrast to low power leaders, should be more immune to the influence of situational cues, and hence less open to performance information.

\section{Leader Self-Serving Behavior and Effective Leadership Beliefs}

From a leadership perspective, role-related schemas are especially likely candidates to serve as internal behavioral guides. Leader categorization theory suggests that leaders have behavioral schemas that pertain directly to the leader role (i.e., implicit leadership theories) and that these 
schemas represent a foundation for the generation of behaviors (Lord \& Maher, 1993; Meindl \& Ehrlich, 1987; van Gils, van Quaquebeke, \& van Knippenberg, in press).

One such specific type of leader behavioral schema is an effective leadership schema. Although typically leader categorization theory has been invoked to show that perceivers hold different schemas for, and associate different behavioral categories with, effective and ineffective leaders (Lord, Foti, \& De Vader, 1984), the theory also includes propositions more relevant to the current analysis, namely that leaders too hold effective leadership schemas. Hence, we argue that leaders hold a schema of an effective leader that "provides a self-standard about how the leader should behave in a given situation" (Lord \& Maher, 1993, p. 132). Needless to say, definitions of leadership effectiveness may vary widely, and leaders may differ in how they envision their role and their relationship to their subordinates. In this respect, most social relationship models suggest that individuals implicitly understand their interactions with others as functioning along a particular dimension: self vs. other-orientation (Fiske, 1992; MacCrimmon \& Messick, 1976; Mills \& Clark, 1984). Thus, leaders can see their role along a continuum of primarily being in the service of the self or of the group, and their effective leadership schemas can vary along the self vs. group-serving dimension. Whereas some leaders may believe that effective leaders should fully take advantage of their status by enjoying the perks associated with their position, others may think that they should renounce their status symbols by forfeiting perks. Hence, the content of effective leadership beliefs (self vs. group-serving) will determine the extent to which leader resource allocations may reflect a self or group-orientation (cf. Rus et al., in press).

However, not all leaders will attend to their effective leadership beliefs (ELBs) equally strongly. Based on our analysis of the effects of power, high power leaders should be more likely to behave according to their own beliefs regarding effective leadership than low power leaders. As a result, high power leaders endorsing self-serving ELBs should make more self-serving allocations than high power leaders endorsing group-serving ELBs. 


\section{Leader Self-Serving Behavior and Performance Information}

Leadership research suggests that performance information may be a particularly strong contextual cue on which leaders may base their allocation decisions. Applications of equity theory (Adams, 1965; Walster, Walster, \& Berscheid, 1978) in the arena of leadership suggest that leaders follow equity rules to decide on resource distributions between themselves and their subordinates (De Cremer, 2003; De Cremer \& van Dijk, 2005, 2008; Samuelson \& Allison, 1994; van Dijk \& De Cremer, 2006). Because leaders generally favor resource distributions that reflect individuals' relative performance, one would expect leaders to distribute resources between the self and their subordinates by comparing their and their underlings' performance. In short, information about leaders' and followers' performance should affect leader resource allocation decisions. In this respect, two performance situations are especially interesting: (1) where the leader outperforms the subordinates and (2) where the subordinates outperform the leader. Based on notions of equity theory, leaders who outperform their subordinates should claim more resources for the self, while leaders who perform worse than their subordinates should claim fewer resources for the self.

But not all leaders will attend to performance information equally strongly. From an approachtheory of power perspective, leader power should moderate the effects of performance information on leader allocations. Because performance information is inherently contextual and situationspecific and high power shields the individual from the effects of situational forces, high power leaders should rely less on performance information when allocating resources than low power leaders. Hence, low power leaders should be more likely to use performance information in their allocation decisions than high power leaders, and they should self-allocate more resources when they outperform their subordinates in contrast to when their subordinates outperform them.

\section{Overview of the Present Research}

In sum, we predict that high power leaders' self-allocations are more in line with their ELBs, whereas low power leaders' allocations are influenced more by performance information. 
Specifically, we test two different interaction hypotheses:

Hypothesis 1: Effective leadership beliefs influence high power leaders' self-allocations more than low power leaders' self-allocations. High power leaders' self-allocations are higher (vs. lower) when the leaders endorse self-serving (vs. group-serving) effective leadership beliefs. Hypothesis 2: Performance information influences low power leaders' self-allocations more than high power leaders' self-allocations. Low power leaders' self-allocations are higher (vs. lower) when the leaders' performance information is high (vs. low).

We opted for a multi-study, multi-method test of our hypotheses. First, to establish causality, we conducted a laboratory experiment (Study 1), where we orthogonally manipulated leader power, ELBs, and performance information. Second, we replicated our findings in a quasi-experiment (Study 2), with a measure of ELBs and a different power manipulation. Third, to increase external validity and to assess a broader array of self-serving behavior, we tested our hypotheses in a survey (Study 3) by assessing leader power, ELBs, performance information, and self-serving behavior in a sample of organizational leaders.

In Study 1 and 2 participants were led to believe that they were the leader of a four-person group engaged in computer-mediated task performance. Whereas in Study 1 the power manipulation consisted of providing leaders with relatively more or less coercive power, in Study 2 we tested our predictions with an alternative power manipulation, an experiential power prime (Galinsky et al., 2003). Previous research attests to the fact that internal beliefs can be situationally induced via experimental manipulations (Chiu, Hong, \& Dweck, 1997; Fishbein \& Ajzen, 1975), and that the effects of manipulations of internal states and beliefs are equivalent to the effects obtained by simply measuring natural variations in these states and beliefs across participants (cf. Anderson, 1995; Chiu et al., 1997; Kray \& Haselhuhn, 2007; Hong, Chiu, Dweck, Lin, \& Wan, 1999). Because our primary aim was to test causal relations between variables, in Study 1 we employed a manipulation of ELBs. To replicate the findings of Study 1 with an operationalization 
that may be assumed to reflect more stable differences in ELBs, in Study 2 and 3 we assessed ELBs as self-report measures varying naturally across leaders. The main dependent variable in Studies 1 and 2 was the amount of resources leaders self-allocated out of a shared resource pool. In Study 3 we extended this by using a questionnaire assessing a broader range of self-serving behavior (e.g., using one's position to secure benefits for the self).

\section{Study 1}

Method

\section{Participants and Design}

One hundred and thirty-six Dutch business administration students (71 females, 65 males) with a mean age of 19.75 years $(S D=2.13)$ participated in exchange for $€ 10$ (approximately US \$ 14). Participants were randomly assigned to the conditions of a 2 (Power: high vs. low) X 2 (ELBs: selfserving vs. group-serving) X 2 (Performance information: high vs. low) between-subjects design.

\section{Procedure and Materials}

Participants arrived in groups of twelve to participate in a computer-mediated study on "virtual group decision making" and were seated in individual computer-equipped cubicles. All instructions, stimuli and dependent measures were presented and recorded by the program software.

After being informed about random assignment to a four-person group, participants learned that their team had a hierarchical structure (i.e., a leader and three subordinates) and that group members would be rewarded for their work. To ensure the credibility of the computer-mediated virtual group interaction space, participants had to wait for the establishment of a bogus "network connection" among team members. Next, they completed a purported cognitive style test. After having answered the cognitive style questions, they learned that their team-leader would be chosen based on the results of this test and that the computer would need a few minutes to score everyone's test results.

Effective leadership beliefs manipulation. At this point, we introduced our effective leadership beliefs (ELBS) manipulation (for similar implicit beliefs manipulations see Anderson, 1995; Chiu et 
al., 1997; Kray \& Haselhuhn, 2007; Hong et al., 1999). The ELBs manipulation was introduced while participants were waiting for their test results and therefore, before they were assigned the leader role. We described the ELBs manipulation as a different, unrelated study performed within our research group. Participants were presented with a short description of a leader's behavior and were asked to think about, and write five reasons why this leader is effective in motivating his/her subordinates. The description of the leader's behavior varied by condition and represented our ELBS manipulation. In the self-serving ELBS condition, participants read:

The leader is driven by, and is committed to his/her personal goals and ambitions. Moreover, he/she invests minimal resources in group tasks and fully makes use of the privileges and status symbols associated with his/her position (such as for example: a company plane, a company car, an executive suite, company stock options, a number of personal assistants).

In the group-serving ELBS condition participants read:

The leader is driven by, and is committed to his/her group's goals and ambitions. Moreover, he/she invests maximal resources in group tasks and fully gives up the privileges and status symbols associated with his/her position (such as for example: a company plane, a company car, an executive suite, company stock options, a number of personal assistants).

After completing the manipulation, participants were informed that the computer had finished the test scoring, and all participants were assigned the leader role allegedly based on their scores.

Next, they learned that their group would work on a number of different tasks and that, as leaders, they were to ensure their team's optimal performance. As leaders, it was their responsibility to motivate their subordinates to perform well and to ensure that they devote their full attention and energy to the tasks at hand. Indeed, it was their duty to decide how the tasks should be completed, to assign specific tasks to employees, to provide subordinates with additional instructions on task implementation, and to ensure that all group tasks were brought to fruition.

Power manipulation. The power manipulation was embedded in the aforementioned leader role description. Although all participants were leaders - and thus, were in higher power positions - 
some had relatively more coercive power than others within that role. In the low power condition, they learned that they only had the power to evaluate subordinates' work for feedback purposes, and could not use these evaluations to fire or reprimand subordinates. Hence, they could neither take disciplinary actions against their subordinates, nor could they fire them for substandard performance. They also learned that they did not have the power to hinder subordinates in their task accomplishment. Conversely, in the high power condition, leaders learned that they had the power to evaluate subordinates' work for feedback purposes, and could use these evaluations to fire or reprimand subordinates. Hence, they could take disciplinary actions against their subordinates and they could fire them for substandard performance. They also learned that they did have the power to hinder subordinates in their task accomplishment.

Performance information manipulation. Next, we informed participants that their team would perform two different tasks: a contrast-sensitivity task (cf. van Knippenberg, van Knippenberg, \& De Cremer, 2007) and a desert survival task (cf. Lafferty \& Pond, 1974). The contrast-sensitivity task was introduced as a cover story for our performance information manipulation. The instructions stressed that the task was designed to measure the degree to which individual team members were contrast-sensitive. Contrast-sensitivity was presented as a trainable ability unrelated to intelligence or mathematical acumen. Participants also read that they would receive privileged information regarding their and their team-mates performance.

The task consisted of estimating as accurately as possible the number of black squares in a checkerboard grid of 180 randomly arranged black and white squares. Participants did not know that each grid always consisted of 90 black and 90 white squares. Each grid was presented for 5 seconds. After two practice rounds, participants estimated the number of black squares in a total of 10 grids. Next, leaders were presented with bogus performance information regarding their and their subordinates' performance. This represented our performance information manipulation. In the high performance information condition, participants read that they had scored 88 points on a scale from 0 
to 100 , while their subordinates had scored 55,53 , and 51 points respectively. In the low performance information condition, leaders read that they had scored 53 points, while their subordinates had scored 86, 88, and 84 points. Participants were also presented with a rank ordering of their and their subordinates' performance, stressing the performance differences within the group. In the high performance condition, the leader was ranked first; in the low performance condition last.

Desert survival task. Next, the desert survival task (cf. Lafferty \& Pond, 1974), which consisted of ranking 12 utensils found after a plane crashed in the desert, started. First, leaders learned that their team could earn 500 points for successful task completion and that the allotted time for this task was 10 min. The leader's job was to delegate 4 of the utensils to each subordinate for ranking purposes, to create the final item ranking, and to motivate subordinates to perform well (via emails).

Participants never arrived at the last stage of the task, the final rank-ordering. After emailing subordinates and delegating the utensils, leaders were asked to divide the 500 points the team could earn between themselves and their employees. After the dependent measures and demographic indicators such as age and gender, participants were thoroughly debriefed, thanked, and paid.

Dependent measures. Our main dependent measure represented the number of points leaders self-awarded. Each compensation point counted as one lottery entry for several 50 euro prizes. Hence, the more points they self-awarded, the higher the chances of winning one of the prizes. Manipulation checks were recorded on a 7-point scale ranging from strongly disagree (1) to strongly agree (7). To check our ELBs manipulation, participants answered eight questions (Rus et al., in press) assessing their beliefs about effective leadership. Four questions pertained to the selfserving and four to the group-serving ELBs (see Appendix A). The four group-oriented items were reverse-scored and all items were averaged into one ELBs score (Cronbach's $\alpha=.95)^{1}$. As a check of our power manipulation, participants responded to an 8-item scale (e.g., "I feel powerful.'; “I feel dependent (R)."; "I feel in control."). The reverse-scored items were recoded and all items were averaged into one power score (Cronbach's $\alpha=.92)^{2}$. To check our performance information 
manipulation, participants answered three questions (i.e., "My score on the contrast-sensitivity task was better than that of my team members."; "My score on the contrast-sensitivity task was worse than that of my team members (R)."; "I performed better than my team members on the contrastsensitivity task.”). The reverse-scored item was recoded and all items were averaged into a performance information score (Cronbach's $\alpha=.97)^{3}$.

\section{Results}

In all analyses of variance (ANOVAs) power (high/low), ELBs (self-serving/group-serving), and performance information (high/low) were factors in the design. Preliminary analyses showed that gender did not interact with any of our manipulations, so we collapsed across gender in all subsequent analyses.

Manipulation checks. A three-way ANOVA on the ELBs score revealed only a significant main effect of ELBs, $F(1,128)=983.96, p<.001, \eta_{\mathrm{p}}^{2}=.88$, with leaders in the self-serving ELBs conditions $(M=5.16, S D=.47)$ being more likely to endorse self-serving ELBs than leaders in the group-serving conditions $(M=2.53, S D=.48)$. A three-way ANOVA on the power score yielded only a significant main effect of power, $F(1,128)=379.331, p<.001, \eta^{2}=.75$, with participants in the high power conditions $(M=5.72, S D=.83)$ feeling more powerful than participants in the low power conditions $(M=3.00, S D=.80)$. A three-way ANOVA on the performance information score revealed only a significant main effect of performance information, $F(1,128)=1139.92, p<$. $001, \eta_{p}^{2}=.90$, with participants in the high performance information condition perceiving that they had performed better $(M=6.38, S D=.60)$ than participants in the low performance information condition $(M=1.82, S D=.92)$. Thus, we may conclude that our manipulations were successful.

Leader allocation decision. A three-way ANOVA on the number of points leaders self-awarded revealed a main effect of ELBs, $F(1,128)=15.06, p<.001, \eta_{\mathrm{p}}^{2}=.10$. Leaders endorsing selfserving ELBs claimed more points $(M=207.51, S D=73.03)$ than those endorsing group-serving ELBs $(M=166.94, S D=56.11)$. The three-way ANOVA on the number of points leaders self- 
awarded also revealed a main effect of performance information, $F(1,128)=11.15, p=.001, \eta_{\mathrm{p}}^{2}=$. 08 , with leaders who believed that they outperformed their subordinates $(M=202.58, S D=68.40)$ self-allocating more points than those who thought their subordinates had outperformed them $(M=$ 168.05, $S D=62.36)$. As predicted, these two main effects were qualified by a Power X ELBs interaction, $F(1,128)=10.52, p=.002, \eta_{\mathrm{p}}^{2}=.07$ (see Figure 1), as well as by a Power $\mathrm{X}$ Performance information interaction, $F(1,128)=11.88, p=.001, \eta_{\mathrm{p}}^{2}=.08$ (see Figure 2). As expected, the three-way interaction was not significant, $F(1,128)=1.94, p=.17, \eta_{\mathrm{p}}^{2}=.01$.

Hypothesis 1 suggests that high power leaders' self-allocations will reflect their ELBs more than low power leaders' self-allocations. Specifically, high power leaders endorsing self-serving ELBs should self-allocate more points than high power leaders endorsing group-serving ELBs. A simple effects analysis of the Power X ELBs interaction, indicated that high power leaders selfawarded more points when they endorsed self-serving ELBs $(M=223.45, S D=69.63)$ than when they endorsed group-serving ELBs $(M=151.11, S D=37.85), F(1,128)=25.18, p<.001, \eta_{\mathrm{p}}^{2}=.16$, CI $($ diff $)=$ between 43.54 and 100.23. No such differential reliance on ELBs was found for low power leaders $\left(M_{S E L B}=192.97, S D=74.03\right.$ vs. $\left.M_{G E L B}=183.23, S D=66.85\right)$. Additionally, high power leaders endorsing self-serving ELBs $(M=223.45, S D=69.63)$ claimed more points than low power leaders endorsing self-serving ELBs $(M=192.97, S D=74.03), F(1,128)=6.12, p=.01, \eta^{2}$ p $=.05, \mathrm{CI}($ diff $)=$ between 7.26 and 65.15 . Congruent with our expectations, high power leaders endorsing group-serving ELBs $(M=151.11, S D=37.85)$ claimed less points than low power leaders endorsing group-serving ELBs $(M=183.23, S D=66.85), F(1,128)=4.42, p=.03, \eta_{\mathrm{p}}^{2}=$. 03, CI (diff) = between -56.75 and -1.74 . This suggests that high power leaders' allocations were significantly influenced by their endorsed ELBs, whereas low power leaders' were not. Importantly, contingent on the nature of the endorsed ELBs (i.e., whether they were self or group-serving), high power leaders' allocations were more self or more group-serving than low power leaders'.

Hypothesis 2 predicts that performance information should affect low power leaders' 
allocations more than high power leaders'. Specifically, low power leaders who thought that they had outperformed their subordinates should claim more points than low power leaders who thought that their subordinates had outperformed them. As predicted, a simple effects analysis of the Power X Performance information interaction, indicated that low power leaders self-awarded more points when they thought they had outperformed their subordinates $(M=217.92, S D=78.24)$ than when they thought their subordinates had outperformed them $(M=149.17, S D=27.32), F(1,128)=$ 23.21, $p<.001, \eta_{\mathrm{p}}^{2}=.15$, CI (diff) $=$ between 40.36 vs. 96.61 . No such differential impact of performance evaluations on the allocation decision was shown by high power leaders $\left(M_{H P I}=\right.$ 184.45, $S D=49.86$ versus $\left.M_{L P I}=184.71, S D=78.47\right), F(1,128)<1$. Moreover, when they perceived to have outperformed their subordinates, low power leaders $(M=217.92, S D=78.24)$ claimed more points than high power leaders $(M=184.45, S D=49.86), F(1,128)=5.10, p=.02$, $\eta_{\mathrm{p}}^{2}=.04$, CI (diff) = between 3.89 and 58.73. Conversely, when they thought their subordinates had outperformed them, low power leaders $(M=149.17, S D=27.32)$ self-allocated less points than high power leaders $(M=184.71, S D=78.47), F(1,128)=6.80, p=.01, \eta_{\mathrm{p}}^{2}=.05, \mathrm{CI}(\mathrm{diff})=$ between -67.30 and -9.24. In line with Hypothesis 2, it appears that high power leaders' selfallocations were relatively unaffected by situational contingencies (i.e., performance information), whereas low power leaders were more likely to factor such external influences into their decisions.

\section{Discussion Study 1}

We predicted that high power leaders' allocations would be more in line with their internal belief states regarding effective leadership (i.e., ELBs) than low power leaders' allocations, and that high power leaders' allocations would be more immune to situational contingencies than low power leaders' allocations. Indeed, the present data support our hypothesized relationships. We found that ELBs impacted high power leaders' allocations more than low power leaders' allocations, and that contingent on the endorsed ELBs, high power leaders' allocations were more or less self-serving. High power leaders endorsing self-serving ELBs acted more self-servingly than high power leaders 
endorsing group-serving ELBs as well as more self-servingly than low power leaders endorsing self-serving ELBs. Conversely, high power leaders endorsing group-serving ELBs acted more group-servingly than low power leaders endorsing group-serving ELBs. These results suggest that high power leaders are more likely than low power leaders to base their allocation decisions on their endorsed ELBs. Additionally, we found that performance information impacted high power leaders' allocations less than low power leaders'. Low power leaders who thought they had outperformed their subordinates claimed more resources than low power leaders who thought they had underperformed their subordinates. Low power leaders who thought they had outperformed their subordinates self-allocated more resources than high power leaders, whereas low power leaders who thought their subordinates had outperformed them self-allocated fewer resources than high power leaders. These data suggest that low power leaders are more likely than high power leaders to base their allocation decisions on both high and low performance information.

Whereas the results of this study are promising, they also leave us with some intriguing questions. First, in line with previous conceptualizations of implicit beliefs (cf. Chiu et al., 1997) we have manipulated internal belief states (i.e., ELBs). Although from a theoretical standpoint manipulation of implicit beliefs should yield similar effects to the measurement of such beliefs, this remains a question to be answered empirically. Hence, in Study 2, we aimed to replicate the results of Study 1 by employing a measure of ELBs. Second, to increase the robustness of our findings, in Study 2, we employed a different power manipulation (Galinsky et al., 2003) than in Study 1.

\section{Study 2}

\section{Method}

\section{Participants and Design}

One hundred and fifty-four Dutch business administration students (76 females, 78 males) participated voluntarily in the study in exchange for $€ 10$ (approximately US \$14). Participants’ mean age was 19.90 years $(S D=1.82)$ and they were randomly assigned to the conditions of a 2 
(Power: high vs. low) X 2 (Performance information: high vs. low) between-subjects design, while ELBs were added to the design as a continuous variable based on pre-manipulation measurement.

\section{Procedure and Materials}

Participants arrived in groups of 16 to the laboratory to complete a number of different tasks, including a computer-mediated study on "virtual group decision making" and were seated in individual computer-equipped cubicles. We followed the paradigm developed for Study 1 with a few modifications. The main differences were (1) the replacement of our ELBs manipulation with a measure of ELBs, and (2) the employment of a different power manipulation.

Effective leadership beliefs measure. The first task participants completed was the ELBs measure which was framed as an independent study, ostentatiously labeled Study 1 . We measured participants' ELBs by using the same 8-item scale that served as our ELBs manipulation check in Study 1 . The four group-serving items were reverse-scored, and all items were averaged into an ELBs score (Cronbach's $\alpha=.91 ; M=2.87 ; S D=.98$ ). After completing the ELBs measure, participants engaged in a three-minute hidden figures task labeled "Study 2". They were presented with ten pictures containing embedded figures and were asked to identify a simple figure in a more complex pattern (cf., Ekstrom, French, Harman, \& Dermen, 1976).

Power manipulation. After the filler task, participants completed an alleged "Study 3" which comprised our power manipulation, which was identical to the experiential prime procedure used by Galinsky et al. (2003). Participants were asked to provide a written report of a particular incident in their lives where they had power over someone else, or where someone else had power over them.

Experimental set-up and performance information manipulation. Next participants started the final study of the session, Study 4. This represented the computer-mediated study on "virtual group decision making" and the experimental set-up was identical to the set-up of Study 1 . The only difference was that we omitted the ELBs manipulation and the original power manipulation. Thus, after being informed about working in a 4-person hierarchical team, completing the cognitive style 
test, being assigned the leader role, and being exposed to our performance information manipulation, participants proceeded to give subordinates instructions for the group task, to email them, and to allocate the points. After the dependent measures and demographic questions pertaining to age and gender, participants were debriefed, thanked, and paid.

Dependent measures. As in Study 1 our main dependent variable was the number of points leaders self-awarded. Manipulation checks were recorded on 7-point scales ranging from strongly disagree (1) to strongly agree (7). To check our power manipulation we used the same power scale as in Study 1 ( 8 items; Cronbach's $\alpha=.93$ ). As a check of our performance information manipulation, participants answered the same 3-item scale (Cronbach's $\alpha=.96$ ) as in Study $1^{4}$.

\section{Results}

All subsequently reported hierarchical regression analyses included main effect terms for power, performance information, and ELBs (at Step 1), all two-way interaction terms (Power X ELBs, Power X Performance information, and Performance information X ELBs) (at Step 2), and the three-way interaction term (Power X ELBs X Performance information) (at Step 3) as predictors. Following Aiken and West (1991), power and performance information were dummycoded - high power and high performance information were coded as .5 , and low power and low performance information were coded as -.5. ELBs were centered by subtracting the mean from each score. The interaction terms and the main effect terms were based on the dummy codes for power and performance information and the centered score for ELBs. Gender was not included in the design as preliminary analyses revealed that it did not interact with any of our predictor variables.

Manipulation checks. To test the success of our power manipulation, we conducted a hierarchical regression analysis on the power score. As expected, Step 1 explained a significant proportion of variance in leaders' reported perceptions of power, adjusted $R^{2}=.71, F(3,150)=$ $122.71, p<.001$. We only found a positive relationship between the power manipulation and leaders' feelings of power, $\beta=.84, t(150)=19.00, p<.001$. Step 2 and Step 3 did not explain an additional 
significant proportion of variance in leaders' psychological experience of power, and only the main effect of power reached significance $(\beta=.84, t(147)=18.89, p<.001$ in Step 2 and $\beta=.84, t(146)$ $=18.68, p<.001$ in Step 3). This suggests that leaders in the high power conditions felt more powerful than leaders in the low power conditions. To test the effectiveness of the performance information manipulation, we conducted a hierarchical regression analysis on the performance information score. Step 1 explained a significant proportion of variance in leaders' perceived performance, adjusted $R^{2}=.84, F(3,150)=267.02, p<.001$. We only found a positive relationship between the performance information manipulation and leaders' perception of their performance, $\beta=$. $92, t(150)=28.15, p<.001$. Step 2 and Step 3 did not explain an additional significant proportion of variance in leaders' perception of their performance, and only the main effect of performance information reached significance $(\beta=.92, t(147)=27.98, p<.001$ in Step 2 and $\beta=.92, t(146)=$ 27.83, $p<.001$ in Step 3). This suggests that leaders in the high performance information conditions felt that they had outperformed their subordinates as compared to leaders in the low performance information conditions. Thus, we may conclude that our manipulations were successful.

Leader allocation decision. To test our hypotheses that high power leaders' actions are more in line with their ELBs and are influenced less by performance information than low power leaders' actions, we conducted a hierarchical regression analysis on leader self-allocations. Table 1 shows the regression results: Step 1 explained a significant proportion of variance in leader self-allocations and we replicated the results of Study 1 by finding a positive relationship between ELBs and leader self-serving allocations, as well as a positive relationship between performance information and leader self-serving allocations. More importantly, Step 2 explained an additional significant proportion of variance in leader allocations and it revealed our predicted Power X ELBs (see Figure 3) and Power X Performance information (see Figure 4) interactions. As expected, the three-way interaction was not significant. 
To further analyze the two-way interactions, we conducted simple slopes analyses (Aiken \& West, 1991) and determined the simple slopes for high and low power leaders separately. As predicted, ELBs yielded a strong positive relationship to leader self-serving allocations for high power leaders $(\beta=.70, p<.001)$ but not for low power leaders $(\beta=-.06, p=.46)$. Also as predicted, performance information yielded a positive relationship to leader self-serving allocations for low power leaders $(\beta=.67, p<.001)$, but not for high power leaders $(\beta=.05, p=.57)$.

\section{Discussion Study 2}

In line with our theoretical framework, we replicated the results of Study 1 in a quasiexperimental setting relying on measurement of natural variation in ELBs. Study 2 again confirms that high power leaders' self-serving behavior is more strongly predicted by their ELBs than low power leaders' behavior, while low power leaders' self-allocations are more strongly influenced by performance information than high power leaders' self-allocations. Importantly, it also does so with another operationalization of power, demonstrating that the pattern of results is not contingent on the specific operationalization of the independent variables used. Studies 1 and 2 do leave open the question, however, whether the same relationships may be observed in the field.

\section{Study 3}

In this study we measured leader power, ELBs, performance information, and self-serving leader behavior in an organizational context. The survey was designed to further bolster the confidence in our conclusions by a replication via a different method, the use of a different research population as well as with a more extended array of self-serving behaviors. While our experimental and quasi-experimental study yielded consistent causal evidence in support of our hypotheses, they do not speak to whether we can find support for our theoretical framework in a field context (i.e., in a sample of organizational leaders). Given that we believe our results to also be of interest to a more applied audience, there is value-added in testing the generalizability of our conclusions to leadership in the field, in addition to bolstering confidence in our findings by establishing that they 
are not limited to a specific research paradigm. Moreover, whereas Study 1 and 2 focused exclusively on monetary allocations, our dependent measure in the survey was more encompassing by also tapping into the allocation of other resources such as time and credit for jobs performed. This allowed us to establish that our findings are not limited to a narrow conceptualization of selfserving behavior. Of less importance but not without merit, although we have no reason to believe that relying on Dutch samples in our experimental studies poses a limitation to the generalizability of our results, we used the opportunity for a replication with a sample from a different country, the United Kingdom.

\section{Method}

Procedure. The study was conducted online as a leadership survey. Respondents were recruited via a panel firm located in the United Kingdom. Emails with personalized survey links were sent to a panel of individuals in managerial positions who had a minimum of three direct subordinates and a minimum of five years of work experience.

The survey was conducted in line with recommendations given in the field (Birnbaum, 2004). By utilizing server-sided survey programming we avoided common technical selection biases, which generally exclude people who do not meet special browser requirements. We also pretested the layout on a number of different computers with varying browsers and screen resolutions to ensure that the survey would look the same on different systems. Each potential respondent was assigned a unique session ID to prevent individuals from participating in the survey more than once. To increase response rate respondents received a monetary incentive. Finally, we guaranteed respondents' anonymity and confidentiality. These measures taken to prevent common pitfalls of online research lead us to be at least as confident about the quality of our data as we would have been had we conducted a traditional paper and pencil survey.

Sample. Two hundred and twenty-eight respondents meeting the study's requirements completed the survey (67\% response rate). The sample's mean age was 42.99 years $(S D=9.76)$ and 
women made up 39\% of the sample. Respondents' average fulltime work experience was 23.21 years $(S D=10.31)$, average tenure in a supervisory position was 12.28 years $(S D=7.96)$, and average tenure on the current job was 6.95 years $(S D=5.17)$. All respondents worked in private organizations and had on average 13.29 subordinates $(S D=14.30)$. Respondents with a higher education degree (i.e., Bachelor degree or higher) made up $71.1 \%$ of the sample and the majority $(84.12 \%)$ held management or senior management positions.

Measures. All responses were assessed on 5-point scales $(1=$ strongly disagree, $5=$ strongly agree). Leader power was measured with 9 items of the Yukl and Falbe (1991) position power scale (the subscales coercive, reward, and legitimate power). We used the original items and only adapted the instructions given to respondents (i.e., "My supervisor can..." was changed to "As a supervisor I can..."). Items were averaged into one leader power score. $E L B S$ were measured with the same 8 items (4 self and 4 group-serving) that were used as ELBs manipulation checks in Study 1 and as a measure of ELBs in Study 2. The group-serving items were reverse-scored and items were combined into an average ELBs score. Leader performance was measured with one item, which was designed to be similar to the performance information leaders had received in Study 1 and 2 (“On average, compared to my subordinates, my performance last year was $1=$ much better; $5=$ much worse; reverse-scored).

An 8-item scale, identical to the one used by Rus et al. (in press) comprised our measure of leader self-serving behavior. Arguably, leaders can act self-servingly by securing higher monetary benefits for themselves, but they can also act self-servingly by making self-serving causal attributions such as taking unwarranted credit for group accomplishments or by denying responsibility for failure on group projects (cf. Weary Bradley, 1978). Whereas in Study 1 and 2, our dependent measure tapped exclusively into the allocation of monetary resources, in the survey we employed a more encompassing measure of self-serving behavior by also assessing the allocation of other resources, such as time and credit for jobs performed. For each of the 8 items 
(see Appendix A), respondents indicated the number of times they had performed the described behavior during the past year $(1=$ never; 2 =rarely; $3=$ sometimes; $4=$ usually; $5=$ always $)$.

We controlled for several variables that could potentially relate to power, ELBs, and leader self-serving behavior, namely respondents' age, gender $(1=$ male, $2=$ female $)$, position tenure (years), number of direct subordinates, self-definition as a leader (8-items; Rus et al., in press), and group identification (4-items; van Knippenberg \& van Knippenberg, 2005).

\section{Results}

Means, standard deviations, reliabilities, and correlations for the study variables are shown in Table 2.

Leader self-serving behavior. To test our hypotheses that (1) high power leaders' actions are more in line with their ELBs than low power leaders' actions, and (2) that high power leaders are influenced less by performance information than low power leaders, we conducted a hierarchical regression analysis in which leader self-serving behavior was predicted by main effect terms for the control variables (age, gender, position tenure, number of subordinates, leader self-definition, group identification) at Step 1, main effect terms for our independent variables (power, ELBs, and performance information) at Step 2, the two-way interaction terms (Power X ELBs, Power X Performance information, and Performance information X ELBs) at Step 3, and the three-way interaction term (Power X ELBs X Performance information) at Step 4. Following Aiken and West (1991), power, ELBs, and performance information were centered by subtracting the mean from each score, and the interaction terms as well as the main effects were based on the centered scores.

Table 3 shows the regression results: Step 1 did not explain a significant proportion of variance in leader self-serving behavior. Step 2, explained a significant proportion of variance and it unveiled a positive relationship between ELBs and leader self-serving behavior. As predicted, Step 3 explained an additional significant proportion of variance in leader self-serving behavior and it revealed our predicted Power X ELBs (see Figure 5) and Power X Performance information (see 
Figure 6) interactions. As expected, Step 4 did not reveal a significant three-way interaction.

To further analyze the interactions, we conducted simple slopes analyses (Aiken \& West, 1991) and determined the simple slopes for high and low power leaders separately. As predicted in Hypothesis 1, ELBs yielded a stronger positive relationship with leader self-serving behavior for high power $(1 S D$ above the mean; $\beta=.54, p<.001)$ than for low power leaders $(1 S D$ below the mean; $\beta=.17, p=.05)$. In support of Hypothesis 2 , performance information yielded a positive relationship to leader self-serving behavior for low power ( $1 S D$ below the mean; $\beta=.25, p=.008$ ), but not for high power leaders (1 $S D$ above the mean; $\beta=-.14, p=.10$ ).

\section{Discussion Study 3}

This study replicates the results obtained in Studies 1 and 2 and shows that the hypothesized relationships may in fact also be observed in a natural setting. Specifically, we found that high power leaders' behaviors were more in line with their ELBs than low power leaders' behaviors, whereas low power leaders' actions were influenced more by performance information than high power leaders' actions. The fact that findings of our earlier studies were replicated with a different methodology, a sample from a different research population as well as with an extended range of leader self-serving behaviors bolsters the confidence in the support for our hypotheses.

\section{General Discussion}

Organizational leaders, who hubristically plunder company coffers to satisfy their own whims and desires at the cost of the collective, face not only public scorn and anger, but also losses in wealth and status. Additionally, self-serving leader behavior has been associated with negative consequences at the organizational level as well as with decreases in subordinate motivation and performance (De Cremer \& van Knippenberg, 2004). In the present study, we aimed to investigate the relationship between leader power and two factors proposed to be vital in understanding leader resource allocations: ELBs and performance information. By marrying insights derived from the power-approach theory (Keltner et al., 2003), equity theory (Adams, 1965), and leader 
categorization theory (Lord \& Maher, 1993), we posited that power would moderate the relative sway of these internal states and external cues on leader self versus group-serving behavior.

Specifically, we expected high power leaders' behavior to be more representative of their ELBs and to be less influenced by performance information than low power leaders' behavior.

Across three studies we consistently showed that leader power interacted with ELBs (i.e., internal belief states) and performance information (i.e., situational information) in predicting leader self-serving allocations. In contrast to low power leaders, the behavior of high power leaders was influenced more by their ELBs than by performance information, whereas low power leaders' behavior was more strongly predicted by performance information than by their ELBs. Hence, based on these contingencies, either higher or lower power leaders acted more self-servingly.

Inevitably, each of the study designs we employed has its drawbacks. Indeed, this is why we opted for a multi-study approach with replication over research paradigms, populations, and operationalizations. Thus, the strengths of one study compensate for the weaknesses of the other, and the most parsimonious and plausible interpretation of results is one that does not rely on particulars of any one of the studies - replication over studies requires an interpretation that holds over studies. Study 1 yields strong experimental evidence, but may raise the question of whether results also hold for more chronic differences in ELBs. Study 2 addresses this question with a measure of ELBs but otherwise high experimental control. Both studies may call into question as to whether results hold for individuals in ongoing leadership roles in the field, and Study 3 establishes this. Study 3, however, may be criticized for its self-report measurement. While there is evidence that self-reports of undesirable behavior can be as accurate as more objective measures (cf. Aquino \& Douglas, 2003; Hindelang, Hirschi, \& Weiss, 1979), the key point here is that Studies 1 and 2 replicate the findings of Study 3 in ways that cannot be attributed to self-report biases. In a similar vein, the cross-sectional single-source design of Study 3 is suboptimal (even though the mostquoted problem of such a design, common method variance, does not pose a threat to conclusions 
based on interactions; Evans, 1985; McClelland \& Judd, 1993), but again the replication over studies renders any interpretation in terms of design issues specific to Study 3 less plausible. The current evidence for our hypotheses across studies employing different methodologies (i.e., laboratory experiment, quasi-experiment, and field survey), different manipulations and measurement of power, both manipulation and measurement of ELBs, and samples from different research populations (i.e., Dutch students, managers and supervisors in the United Kingdom) thus substantially bolsters the confidence in our findings.

\section{Implications for the Study of Leader Self-Serving Behavior}

Our work suggests that leader power moderates the extent to which leader self-serving versus group-serving behavior is contingent upon effective leadership beliefs (i.e., internal states) and performance information (i.e., external cues). Thus, we have shown that both more powerful and less powerful leaders can act self-servingly contingent on the information they base their decisions on. Not only does this analysis paint a more nuanced picture of the relationship between leader power and leader derailment than prior discussions of self-serving leadership would suggest, it also brings conceptual coherence to the study of the determinants of leader (self-serving) behavior by identifying power as a moderator of the impact of internal states and external cues on leader behavior. The present study not only extends and develops leadership research through its unique focus on power variations within the leader role. It also extends and develops prior power research (1) by focusing on power variations within the higher-power position (i.e., the leader is always more powerful than followers) rather than comparing the less powerful and the more powerful party in a relationship, (2) by relating power to leader self-serving and group-serving behavior, and (3) by focusing on power's interplay with factors that have previously not been considered in power research because they are either uniquely associated with leadership (i.e., ELBs) or have featured prominently in analyses of leader self-serving behavior (i.e., equity concerns).

By focusing on power as a determinant of leader actions we followed a call by House and 
Aditya (1997) for more systematic inquiry into the antecedents of leader behavior and added a social-psychological perspective to the dearth of empirical research on determinants of leader actions. Surprisingly, as compared to the voluminous body of work on leadership effectiveness, research on antecedents of leader behavior has been scant, and has largely focused on individual differences (Bono \& Judge, 2004) and on factors affecting leadership development (Day, 2001).

Our finding that leader power moderates the effects of internal and contextual cues on leader self-serving behavior has a number of implications for the study of leader behavior in general, and self-serving behavior in particular. First, it seems that high power leaders do indeed follow their internal radar more than situational cues when making allocation decisions. Whereas in this research we zoomed in on leaders' beliefs regarding leadership effectiveness, future studies trying to elucidate leaders' decision making processes in resource allocation contexts could focus on their dispositional attributes, such as social values (MacCrimmon \& Messick, 1976) or social relationship orientation (Mills \& Clark, 1984), as well as on affective influences, such as leader moods which have been associated with cooperative and competitive tendencies and might also feed into self-serving tendencies (cf. Forgas \& George, 2001). Moreover, other personality traits such as perceived self-worth and personal fear of invalidity (Thompson, Naccarato, Parker, \& Moskowitz, 2001) appear to be especially worthwhile candidates for explaining leader self-serving behavior. In this vein, Fast and Chen (2009) showed that powerful individuals who perceived themselves to be incompetent displayed more aggression than powerful individuals who felt competent, and that these effects were mediated by perceived ego threat. Importantly, they found that increasing powerful individuals' sense of self-worth resulted in decreased aggression. Also, whereas in this research we have focused on ELBs as internal sources of information, future research could benefit from taking a cross-cultural perspective by exploring how culturally-induced beliefs about what power is and how it should be used impact leader self versus group-serving behavior. Given that there appear to be cultural differences in the conceptualization of power with 
Eastern cultures associating power with responsibility and restraint in contrast to Western cultures where power is associated with rewards and freedom from constraints (Zhong, Galinsky, Magee, \& Maddux, 2009), our present findings may be culturally circumscribed. In sum, in line with the present argument, we expect high power, in contrast to low power leaders, to rely more on these internal states (be they dispositions, moods, culturally-induced beliefs or otherwise) in allocating resources. Likewise, we should expand the range of external cues considered as influences on lower-power leaders' (self-serving) behavior. In addition to performance information, leader behavior may, for instance, be informed by group or organizational normative expectations. Exploring a variety of internal and external forces exerting their sway on leader behavior could further develop the current conceptual framework in which leader power is accorded a key role in moderating the impact of these potential influences on leader behavior.

Second, while our study shows that power in and of itself is not a negative force, the tendency for high power leaders to pay little heed to external cues does have its drawbacks. Previous research has amply demonstrated that a lack of perspective-taking (i.e., the inability to see the world from another person's perspective) associated with high power can lead to stereotyping and subordinate derogation (e.g., Fiske, 1993; Galinsky et al., 2006). In terms of the present analysis, high power leaders' insufficient attention to external information may give rise to simplified, stereotypic perceptions of, and inconsiderate responses to subordinates. While clearly some leaders may be driven by an understanding of their role in terms of their responsibility to their subordinates (i.e., group-serving ELBs) others may not. Under those circumstances, leaders' perspective-taking abilities could provide an alternative route to eliciting socially responsible behavior from high power leaders. Perspective-taking, as an individual difference variable or as a trainable ability, could serve to direct high power leaders' attention towards their subordinates' thoughts and feelings, and by doing so prompt them to act in ways that are considerate of their followers. Clearly, this is an issue to be explored in future research rather than a conclusion that can be drawn from the 
present data, but it is a direction for future inquiry that can be derived from the current findings and speaking to the promise of the current theoretical perspective on leader power in developing our understanding of the determinants of leader self-serving behavior.

Third, we have found converging evidence that high power leaders' behavior is less encumbered by situational constraints and more likely to be rooted in their internal beliefs. Yet, unfortunately our studies do not provide empirical evidence pertaining to the underlying processes that may explain these effects. Therefore, they cannot provide conclusive statements as to whether this is due to a lack of attention or rather to a disregard of external information. Clearly, high power leaders paid at least to a certain extent attention to the performance information, based on their answers to the performance information manipulation checks, but then chose not to use it in their decisions. Arguably both processes (lack of attention and disregard) operate to a certain extent (cf. Galinsky et al., 2008) and it might be fruitful for future research to delve deeper into this issue.

Finally, we may also note that it would be worthwhile to explore the extent to which similar processes may play for individuals in non-leadership roles. Clearly, an influence like ELBs should be unique to leadership, but the more general principle may hold for the effects of power on selfserving behavior for individuals who do not occupy leadership positions.

\section{To Conclude}

Leader self-serving actions are a particularly pernicious class of leadership behavior carrying the specter of negative consequences for subordinates as well as for the organization at large. It is surprising that leadership research to date has hardly concerned itself with factors causing leader self-serving behavior. As such, the present research hopes to have opened a new avenue for exploring factors causing leaders to act self-servingly by pointing at the value of a power analysis. 


\section{References}

Adams, J. S. (1965). Inequity in social exchange. In L. Berkowitz (Ed.), Advances in experimental social psychology. New York: Academic Press.

Aiken, L. S., \& West, S. G. (1991). Multiple regression: Testing and interpreting interactions. Thousand Oaks, CA: Sage Publications.

Anderson, C. A. (1995). Implicit personality theories and empirical data: Biased assimilation, belief perseverance and change, and covariation detection sensitivity. Social Cognition, 13, 25-48.

Anderson, C., \& Berdahl, J. L. (2002). The experience of power: Examining the effects of power on approach and inhibition tendencies. Journal of Personality and Social Psychology, 83, $1362-1377$.

Anderson, C., Keltner, D., \& John, O. P. (2003). Emotional convergence between people over time. Journal of Personality \& Social Psychology, 84, 1054-1068.

Aquino, K., \& Douglas, S. (2003). Identity threat and antisocial behavior in organizations: The moderating effects of individual differences, aggressive modeling and hierarchical status. Organizational Behavior and Human Decision Processes, 90, 195-208.

Aquino, K., \& Reed II, A. (1998). A social dilemma perspective on cooperative behavior in organizations: The effects of scarcity, communication, and unequal access on the use of a shared resource. Group and Organization Management, 23, 390-413.

Bargh, J. A., Raymond, P., Pryor, J. B., \& Strack, F. (1995). Attractiveness of the underling: An automatic power $\rightarrow$ sex association and its consequences for sexual harassment and aggression. Journal of Personality and Social Psychology, 68, 768-781.

Berdahl, J. L., \& Martorana, P. (2006). Effects of power on emotion and expression during a controversial group discussion. European Journal of Social Psychology, 36, 497-509.

Birnbaum, M. H. (2004). Human research and data collection via the Internet. Annual Review of Psychology, 55, 803-832. 
Bono, J. E., \& Judge, T. A. (2004). Personality and transformational and transactional leadership: A meta-analysis. Journal of Applied Psychology, 89, 901-910.

Chen, S., Lee-Chai, A. Y., \& Bargh, J. A. (2001). Relationship orientation as a moderator of the effects of social power. Journal of Personality and Social Psychology, 80, 173-187.

Chiu, C. Y., Hong, Y. Y., \& Dweck, C. S. (1997). Lay dispositionism and implicit theories of personality. Journal of Personality and Social Psychology, 73, 19-30.

Choi, Y., \& Mai-Dalton, R. R. (1999). The model of followers' responses to self-sacrificial leadership: An empirical test. The Leadership Quarterly, 10, 397-421.

Day, D. V. (2001). Leadership development: A review in context. The Leadership Quarterly, 11, 581-613.

De Cremer, D. (2003). How self-conception may lead to inequality: Effect of hierarchical roles on the equality rule in organizational resource-sharing tasks. Group and Organization Management, 28, 282-302.

De Cremer, D., \& van Dijk, E. (2005). When and why leaders put themselves first: Leader behavior in resource allocations as a function of feeling entitled. European Journal of Social Psychology, 35, 553-563.

De Cremer, D., \& van Dijk, E. (2008). Leader follower effects in resource dilemmas: The roles of leadership selection and social responsibility. Group Processes and Intergroup Relations, 11, 355-369.

De Cremer, D., \& van Knippenberg, D. (2003). Cooperation with leaders in social dilemmas: On the effects of procedural fairness and outcome favorability in structural cooperation. Organizational Behavior and Human Decision Processes, 91, 1-11.

De Cremer, D., \& van Knippenberg, D. (2004). Leader self-sacrifice and leadership effectiveness: The moderating role of leader self-confidence. Organizational Behavior and Human Decision Processes, 95, 140-155. 
Ekstrom, R. B., French, J. W., Harman, H. H., \& Dermen, D. (1976). Manual for the kit of factorreferenced cognitive tests. Princeton, NJ: Educational Testing Service.

Evans, M. G. (1985). A Monte Carlo study of the effects of correlated method variance in moderated regression analysis. Organizational Behavior and Human Decision Processes, 36, 305-323.

Farmer, S. M., \& Aguinis, H. (2005). Accounting for subordinate perceptions of supervisory power: An identity-dependence model. Journal of Applied Psychology, 90, 1069-1083.

Fast, N. J., \& Chen, S. (2009). Power, incompetence, and aggression. Psychological Science, 20, $1406-1413$

Fishbein, M., \& Ajzen, I. (1975). Belief, attitude, intention, and behavior: An introduction to theory and research. Reading, MA: Addison-Wesley.

Fiske, A. P. (1992). The four elementary forms of sociality: Framework for a unified theory of social relations. Psychological Review, 99, 689-723.

Fiske, S. T. (1993). Controlling other people: The impact of power on stereotyping. American Psychologist, 48, 621-628.

Forgas, J. P., \& George, J. M. (2001). Affective influences on judgments and behavior in organizations: An information processing perspective. Organizational Behavior and Human. Decision Processes, 86, 3-34.

French, J. P., \& Raven, B. (1959). The bases of social power. In D. Cartwright (Ed.), Studies in social power (pp. 150-165). Ann Arbor, MI: Institute for Social Research.

Galinsky, A. D., Gruenfeld, D. H., \& Magee, J. C. (2003). From power to action. Journal of Personality and Social Psychology, 85, 453-466.

Galinsky, A. D., Magee, J. C., Gruenfeld, D. H., Whitson, J., \& Liljenquist, K. (2008). Power reduces the press of the situation: Implications for creativity, conformity, and dissonance. Journal of Personality and Social Psychology, 95, 1450-1466. 
Galinsky, A. D., Magee, J. C., Inesi, M. E., \& Gruenfeld, D. H. (2006). Power and perspectives not taken. Psychological Science, 17, 1068-1074.

Guinote, A. (2007a). Power and goal pursuit. Personality and Social Psychology Bulletin, 33, 1076-1087.

Guinote, A. (2007b). Power affects basic cognition: Increased attentional inhibition and flexibility. Journal of Experimental Social Psychology, 43, 685-697.

Guinote, A., Judd, C. M., \& Brauer, M. (2002). Effects of power on perceived and objective group variability: Evidence that more powerful groups are more variable. Journal of Personality and Social Psychology, 82, 708-721.

Hindelang, M. J., Hirschi, T., \& Weiss, J. G. (1979). Correlates of delinquency: The illusion of discrepancy between self-report and official measures. American Sociological Review, 44, 995-1014.

Hong, Y. Y., Chiu, C. Y., Dweck, C. S., Lin, D. M. S., \& Wan, W. (1999). Implicit theories, attributions and coping: A meaning system approach. Journal of Personality and Social Psychology, 77, 588-599.

House, R. J., \& Aditya, R. N. (1997). The social scientific study of leadership: Quo vadis? Journal of Management, 23, 409-473.

Keltner, D., Gruenfeld, D. H., \& Anderson, C. (2003). Power, approach, and inhibition. Psychological Review, 110, 265-284.

Kray, L. J., \& Haselhuhn, M. (2007). Implicit negotiation beliefs and performance: Longitudinal and experimental evidence. Journal of Personality and Social Psychology, 93, 49-64.

Lafferty, J. C., \& Pond, A. W. (1974). The desert survival situation. Plymouth, MI: Human Synergistics.

Lord, R. G., Foti, R. J., \& De Vader, C. L. (1984). A test of leadership categorization theory: Internal structure, information processing, and leadership perceptions. Organizational 
Behavior and Human Performance, 34, 343-378.

Lord, R. G., \& Maher, K. J. (1993). Leadership and information processing: Linking perceptions and performance. New York: Routledge.

MacCrimmon, K. R., \& Messick, D. M. (1976). A framework for social motives. Behavioral Science, 21, 86-100.

Magee, J. C., Galinsky, A. D., \& Gruenfeld, D. H. (2007). Power, propensity to negotiate, and moving first in competitive interactions. Personality and Social Psychology Bulletin, 33, $200-212$

McClelland, G. H., \& Judd, C. M. (1993). Statistical difficulties of detecting interactions and moderator effects. Psychological Bulletin, 114, 376-390.

Meindl, J. R., \& Ehrlich, S. B. (1987). The romance of leadership and the evaluation of organizational performance. Academy of Management Journal, 30, 91-109.

Mills, J., \& Clark, M. S. (1984). Exchange and communal relationships. In L. Wheeler (Ed.), Review of personality and social psychology (Vol. 3, pp. 121-144). Beverly Hills, CA: Sage.

Rus, D., van Knippenberg, D., \& Wisse, B. (in press). Leader self-definition and leader self-serving behavior. The Leadership Quarterly.

Samuelson, C. D., \& Allison, S. T. (1994). Cognitive factors affecting the use of social decision heuristics in resource-sharing tasks. Organizational Behavior and Human Decision Processes, $58,1-27$

Tannenbaum, A. (1968). Control in organizations. New York: McGraw-Hill.

Thompson, M. M., Naccarato, M. E., Parker, K. C. H., \& Moskowitz, G. B. (2001). The personal need for structure and personal fear of invalidity measures: Historical perspectives, current applications, and future directions. In G. Moskowitz (Ed.), Cognitive social psychology: The Princeton symposium on the legacy and future of social cognition (pp. 19-39). Mahwah, NJ: Erlbaum. 
van Dijk, E., \& De Cremer, D. (2006). Self-benefitting behavior in the allocation of scarce resources: Leader-follower differences and the moderating effect of social value orientations. Personality and Social Psychology Bulletin, 32, 1352-1361.

van Gils, S., van Quaquebeke, N., \& van Knippenberg, D. (in press). The X-factor: On the relevance of implicit leadership and followership theories for leader-member exchange (LMX) agreement. European Journal of Work and Organizational Psychology.

van Kleef, G. A., De Dreu, C. K. W., Pietroni, D., \& Manstead, A. S. R. (2006). Power and emotion in negotiation: Power moderates the interpersonal effects of anger and happiness on concession making. European Journal of Social Psychology, 36, 557-581.

van Knippenberg, B., \& van Knippenberg, D. (2005). Leader self-sacrifice and leadership effectiveness: The moderating role of leader prototypicality. Journal of Applied Psychology, $90,25-37$

van Knippenberg, B., van Knippenberg, D., \& De Cremer, D. (2007). Why people resort to coercion: The role of utility and legitimacy. European Journal of Social Psychology, 37, 276-287.

Walster, E., Walster, W., \& Berscheid, E. (1978). Equity: Theory and research. Boston: Allyn \& Bacon.

Weary Bradley, G. (1978). Self-serving biases in attribution process: A re-examination of the fact or fiction question. Journal of Personality and Social Psychology, 36, 56-71.

Yukl, G. A., \& Falbe, C. M. (1991). Importance of different power sources in downward and lateral relations. Journal of Applied Psychology, 76, 416-423.

Zhong, C., Galinsky, A. D., Magee, J. C., \& Maddux, W. W. (2009). The cultural contingency of power: Conceptual associations and behavioral consequences. Manuscript submitted for publication. 


\section{Appendix A}

Measures for Study 1, Study 2 and Study 3

\section{ELBs manipulation checks/measure (Rus, van Knippenberg, \& Wisse, in press)}

1. To be effective, a leader should pursue his or her own goals even if this would come at the expense of his or her group's goals.

2. A leader concerned with his or her personal outcomes is effective.

3. An effective leader fully takes advantage of perks such as a company car, a larger office, and company stock options.

4. A leader is effective if he or she invests little time and effort into group tasks.

5. To be effective, a leader should always pursue group goals even if this would come at the expense of his or her personal goals (R).

6. A leader concerned with group outcomes is effective (R).

7. An effective leader gives up perks such as a company car, a larger office, and company stock options (R).

8. A leader is effective if he or she invests time and effort beyond the call of duty into group tasks (R).

\section{Leader self-serving behavior measure (Rus, van Knippenberg, \& Wisse, in press)}

1. I have negotiated a bonus for myself that was substantially higher than the bonus my subordinates received

2. I have used my leadership position to obtain benefits for myself.

3. I have pursued my personal interests, even if those interests were not serving my group's interests.

4. I did not put my own position at risk, even when I thought that this could have helped promote my group's goals.

5. Instead of giving credit to my subordinates for jobs requiring a lot of time and effort, I took the credit myself.

6. Although I was partly to be blamed, I did not take personal responsibility for my group's failure to meet a goal.

7. I have shifted the blame for a mistake of mine onto one of my subordinates.

8. I did not work overtime, although this would have helped my group meet its goals. 


\section{Footnotes}

${ }^{1}$ We also measured whether participants in the self- and group-serving ELBs conditions differed in the perceived difficulty of generating reasons for the described leaders' effectiveness, counted the number of words they wrote as part of the ELBs manipulation, and recorded the amount of time they spent writing. As expected, we found no significant differences between conditions. Finally, we checked whether the reasons they wrote to justify the leader's effectiveness were in line with our manipulation. All participants completed the manipulation as required.

${ }^{2}$ Conceptually leader power is different from self-definition as a leader and perceived legitimacy of the leader role. However, it could be possible that power may affect leader self-definition or the perceived legitimacy of the leader role. Hence, we assessed the degree to which leaders self-defined as leaders and the degree to which they perceived their leadership position as legitimate (see Rus et al., in press). We found no effects of our manipulations on self-definition as a leader or on the perceived legitimacy of the leader role.

${ }^{3}$ We also assessed participants' mood, perceived leader self-efficacy, and group identification (van Knippenberg \& van Knippenberg, 2005). Analyses revealed no significant effects of our manipulations on any of these variables. Conditions did also not differ in actual performance on the contrastsensitivity task. Introducing actual performance as a covariate in our analyses does not change the significance or pattern of our results.

${ }^{4}$ Similar to Study 1, we assessed participants' mood, feelings of leader self-efficacy, perceived legitimacy of the leader role, self-definition as a leader, and group identification. We neither found significant effects of our manipulations nor of our ELBs measure on any of these variables. Additionally we found no effects of our manipulations or of our ELBs measure on participants' actual performance on the contrast-sensitivity task. Introducing these actual performance scores as controls in our regression analyses does not change the significance or pattern of our results. 
Table 1. Summary of Regression Analysis for Power, ELBs, and Performance Information Predicting Leader Self-allocations in Study 2

\begin{tabular}{|c|c|c|c|c|c|c|c|c|c|}
\hline \multirow[b]{2}{*}{ Variable } & \multicolumn{3}{|l|}{ Step 1} & \multicolumn{3}{|l|}{ Step 2} & \multicolumn{2}{|c|}{ Step 3} & \multirow[b]{2}{*}{$\beta$} \\
\hline & $b$ & $S E b$ & B & $b$ & $S E b$ & $\beta$ & $b$ & $S E b$ & \\
\hline Power & 4.62 & 7.52 & .04 & 2.66 & 6.41 & .02 & 2.69 & 6.48 & .02 \\
\hline Effective Leadership beliefs & 19.06 & 3.80 & $.35 * * *$ & 17.14 & 3.35 & $.32 * * *$ & 17.14 & 3.37 & $.32 * * *$ \\
\hline Performance information & 35.87 & 7.56 & $.33 * * *$ & 38.64 & 6.43 & $.36^{* * *}$ & 38.66 & 6.48 & $.36 * * *$ \\
\hline $\begin{array}{l}\text { Power x Effective Leadership } \\
\text { beliefs }\end{array}$ & & & & 41.32 & 6.50 & $.38 * * *$ & 41.37 & 6.74 & $.38^{*}$ \\
\hline Power x Performance information & & & & -66.94 & 12.91 & $-.31 * * *$ & -66.95 & 12.95 & $-.31 *$ \\
\hline $\begin{array}{l}\text { Performance information } \mathrm{x} \\
\text { Effective Leadership beliefs }\end{array}$ & & & & 1.03 & 6.72 & .01 & 1.04 & 6.75 & .01 \\
\hline $\begin{array}{l}\text { Power x Effective Leadership } \\
\text { beliefs x Performance information }\end{array}$ & & & & & & & -.43 & 13.49 & -.00 \\
\hline$\Delta R^{2}$ & & & & & .21 & & & .00 & \\
\hline$R^{2}$ & & & & & .48 & & & .48 & \\
\hline$F$ & & $.55^{* * *}$ & & & $22.96 * * *$ & & & $19.55^{* * *}$ & \\
\hline$D f$ & & 150 & & & 147 & & & 146 & \\
\hline
\end{tabular}

Note. $N=154$ (listwise). ${ }^{*} p<.05 .{ }^{* *} p \leq .01 .{ }^{* *} p \leq .001$. 
Table 2. Means, Standard Deviations, Reliabilities, and Correlations for Study 3

\begin{tabular}{|c|c|c|c|c|c|c|c|c|c|c|c|c|}
\hline & $M$ & $S D$ & (1) & (2) & (3) & (4) & (5) & (6) & (7) & (8) & (9) & (10) \\
\hline (1) Age & 42.99 & 9.76 & $\mathrm{n} / \mathrm{a}$ & & & & & & & & & \\
\hline (2) Gender & 1.39 & .48 & $-.24 * *$ & $\mathrm{n} / \mathrm{a}$ & & & & & & & & \\
\hline (3) Position tenure & 6.95 & 5.17 & $.40^{* *}$ & -.08 & $\mathrm{n} / \mathrm{a}$ & & & & & & & \\
\hline (4) Number of subordinates & 13.29 & 14.30 & .09 & -.05 & $21 *$ & $\mathrm{n} / \mathrm{a}$ & & & & & & \\
\hline (5) Leader self-definition & 3.43 & .59 & -.07 & -.11 & .00 & .13 & $(.86)$ & & & & & \\
\hline (6) Group indentification & 3.79 & .58 & .10 & & .05 & .04 & $.16^{*}$ & (.78) & & & & \\
\hline (7) Power & 3.16 & .77 & -.01 & & -.04 & .11 & .12 & $-.15^{*}$ & $(.82)$ & & & \\
\hline (8) Effective leadership beliefs & 2.18 & .48 & & 0 & -.05 & .05 & -.06 & $-.27 * *$ & .11 & $(.82)$ & & \\
\hline (9) Performance information & 2.32 & .70 & & -.07 & .08 & -.02 & $-.18 * *$ & .04 & -.10 & .05 & $\mathrm{n} / \mathrm{a}$ & \\
\hline (10) Leader self-serving behavior & 2.40 & .43 & & -.06 & .05 & -.01 & -.07 & -.09 & .08 & $.35^{* *}$ & .07 & $(.85)$ \\
\hline
\end{tabular}

Note. $N=228$. Cronbach's alphas are displayed on the diagonal. ${ }^{*} p<.05 .{ }^{*} p<.01$. 
Table 3. Summary of Regression Analysis for Power, ELBs, and Performance Information Predicting Leader Self-serving Behavior in Study 3

\begin{tabular}{|c|c|c|c|c|c|c|c|c|c|c|c|c|}
\hline \multirow[b]{2}{*}{ Variable } & \multicolumn{3}{|c|}{ Step 1} & \multicolumn{3}{|c|}{ Step 2} & \multicolumn{3}{|l|}{ Step 3} & \multicolumn{3}{|c|}{ Step 4} \\
\hline & $b$ & $S E b$ & $ß$ & $b$ & $S E b$ & $ß$ & $b$ & $S E b$ & B & $b$ & $S E b$ & $\beta$ \\
\hline Age & -.00 & .00 & -.07 & .00 & .00 & -.00 & .00 & .00 & .00 & -.00 & .00 & .00 \\
\hline Gender & -.07 & .06 & -.08 & -.03 & .06 & -.03 & 0 & .06 & .00 & .00 & .06 & .00 \\
\hline Position tenure & .00 & .00 & .08 & .00 & .00 & .08 & .00 & .00 & .05 & .00 & .00 & .06 \\
\hline Number of direct subordinates & .00 & .00 & -.01 & -.00 & .00 & -.04 & -.00 & .00 & -.06 & -.00 & .00 & -.06 \\
\hline Leader self-definition & -.05 & .05 & -.07 & -.04 & .05 & -.05 & -.04 & .05 & -.06 & -.05 & .05 & -.06 \\
\hline Group identification & -.05 & .05 & -.07 & .02 & .05 & .02 & .02 & .05 & .02 & .02 & .05 & .02 \\
\hline \multicolumn{4}{|l|}{ Power } & .03 & .04 & .06 & .05 & .03 & .09 & .06 & .04 & .10 \\
\hline \multicolumn{4}{|l|}{ Effective Leadership beliefs } & .30 & & $.34 * * *$ & .32 & .06 & $.36^{* * *}$ & .32 & .06 & $.36^{* * *}$ \\
\hline \multicolumn{4}{|l|}{ Performance information } & .02 & & .03 & .03 & .04 & .06 & .04 & .04 & .06 \\
\hline \multicolumn{4}{|l|}{$\begin{array}{l}\text { Power x Effective Leadership } \\
\text { beliefs }\end{array}$} & & & & .21 & .07 & $.19 * *$ & .22 & .07 & $.20 * *$ \\
\hline \multicolumn{4}{|l|}{ Power x Performance information } & & & & -.15 & .05 & $-.20 * *$ & -.16 & .05 & $-.21 * *$ \\
\hline \multicolumn{3}{|l|}{$\begin{array}{l}\text { Performance information } \mathrm{x} \\
\text { Effective Leadership beliefs }\end{array}$} & & & & & .06 & .08 & .05 & .05 & .08 & .04 \\
\hline \multicolumn{3}{|c|}{$\begin{array}{l}\text { Power x Effective Leadership beliefs } \\
\text { x Performance information }\end{array}$} & & & & & & & & -.06 & .11 & -.04 \\
\hline \multicolumn{2}{|l|}{$\Delta R^{2}$} & & & & .12 & & & .05 & & & .00 & \\
\hline \multicolumn{2}{|l|}{$R^{2}$} & .02 & & & .14 & & & .19 & & & .19 & \\
\hline \multicolumn{2}{|l|}{$F$} & .87 & & & $3.84 * * *$ & & & $4.29 * * *$ & & & $3.97 * * *$ & \\
\hline \multicolumn{2}{|l|}{$D f$} & 221 & & & 218 & & & 215 & & & 214 & \\
\hline
\end{tabular}

Note. $N=228$ (listwise). ${ }^{*} p<.05 .{ }^{* *} p<.01 .{ }^{* * *} p<.001$. 
Figure 1

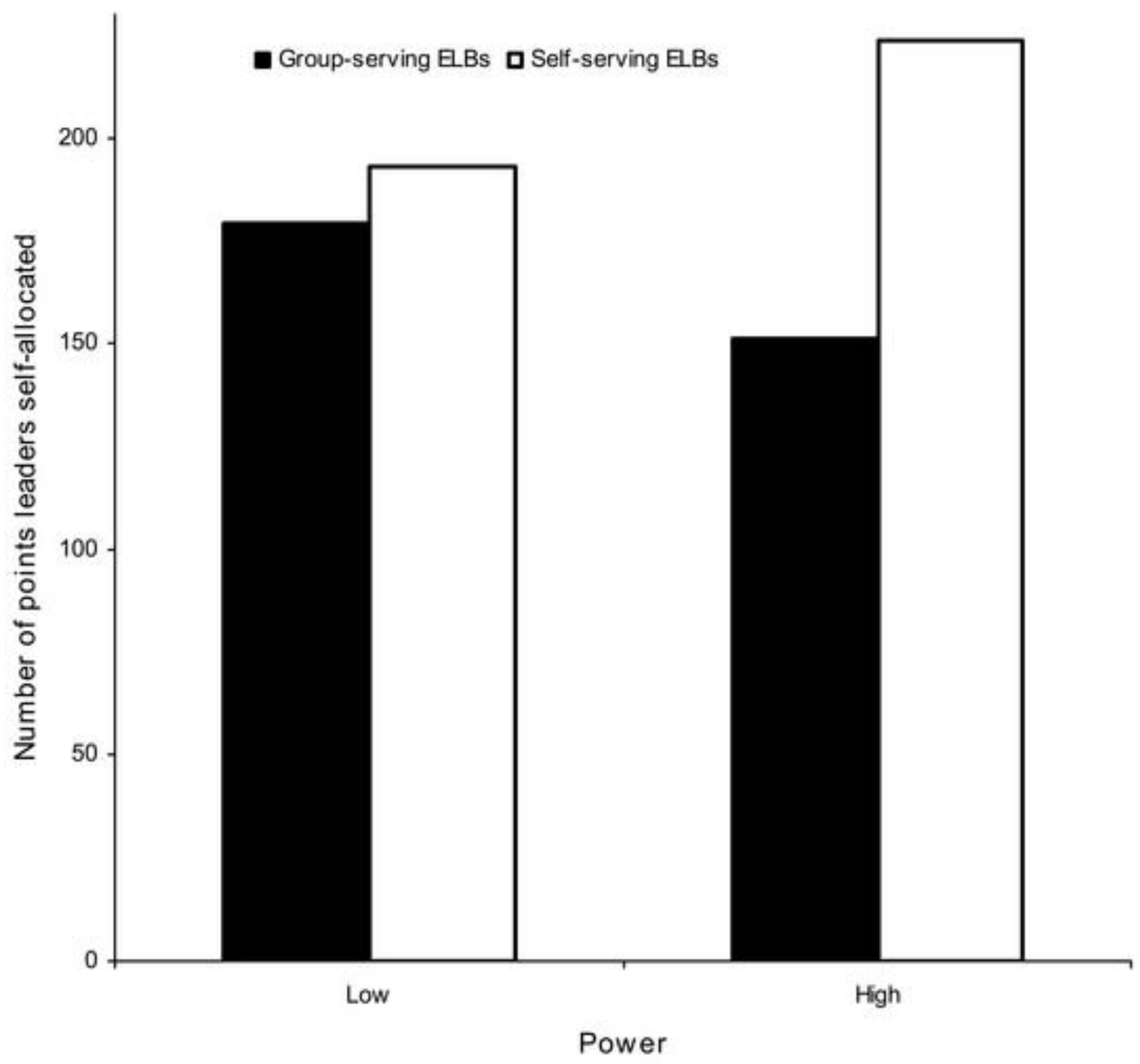


Figure 2

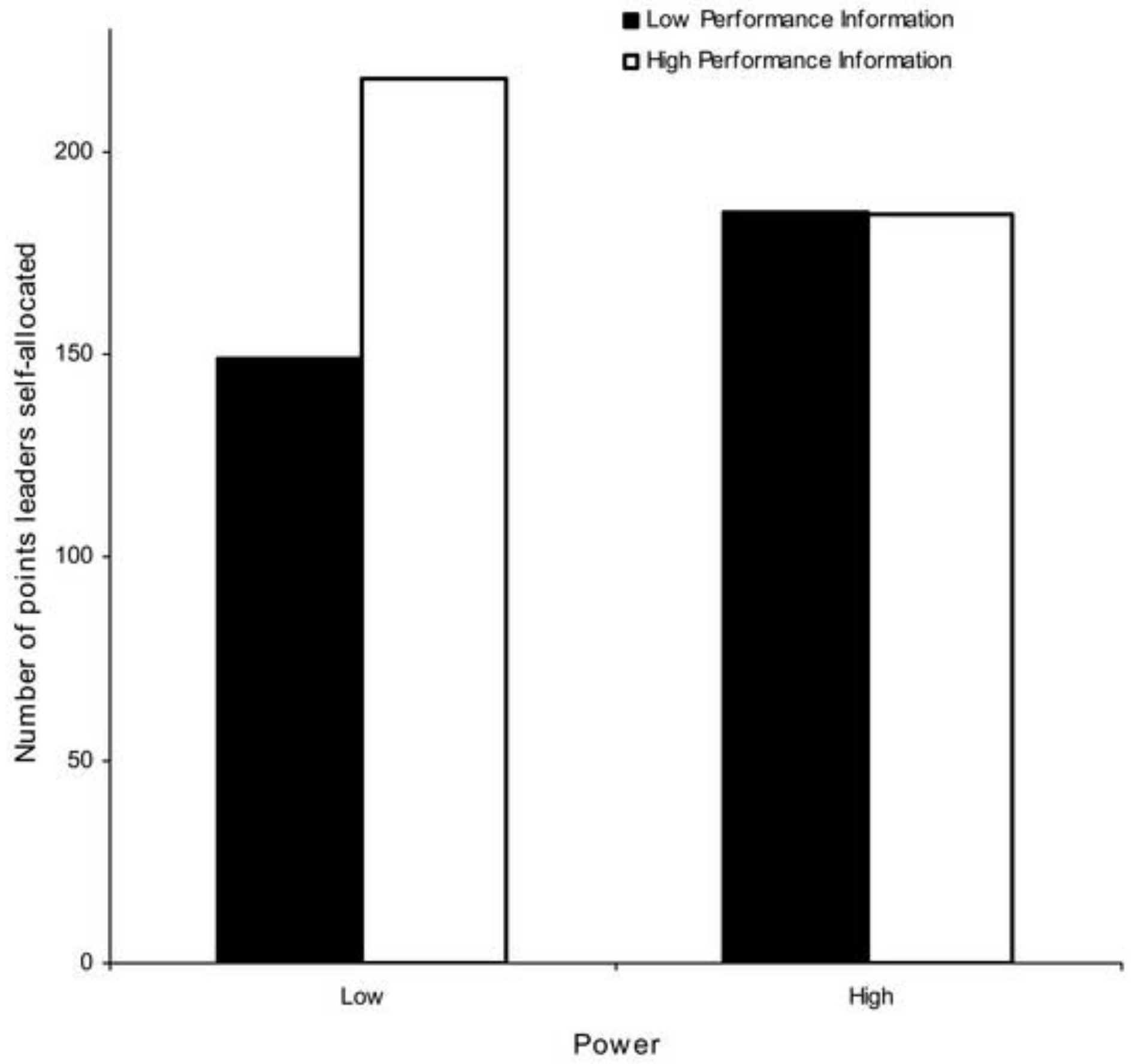


Figure 3

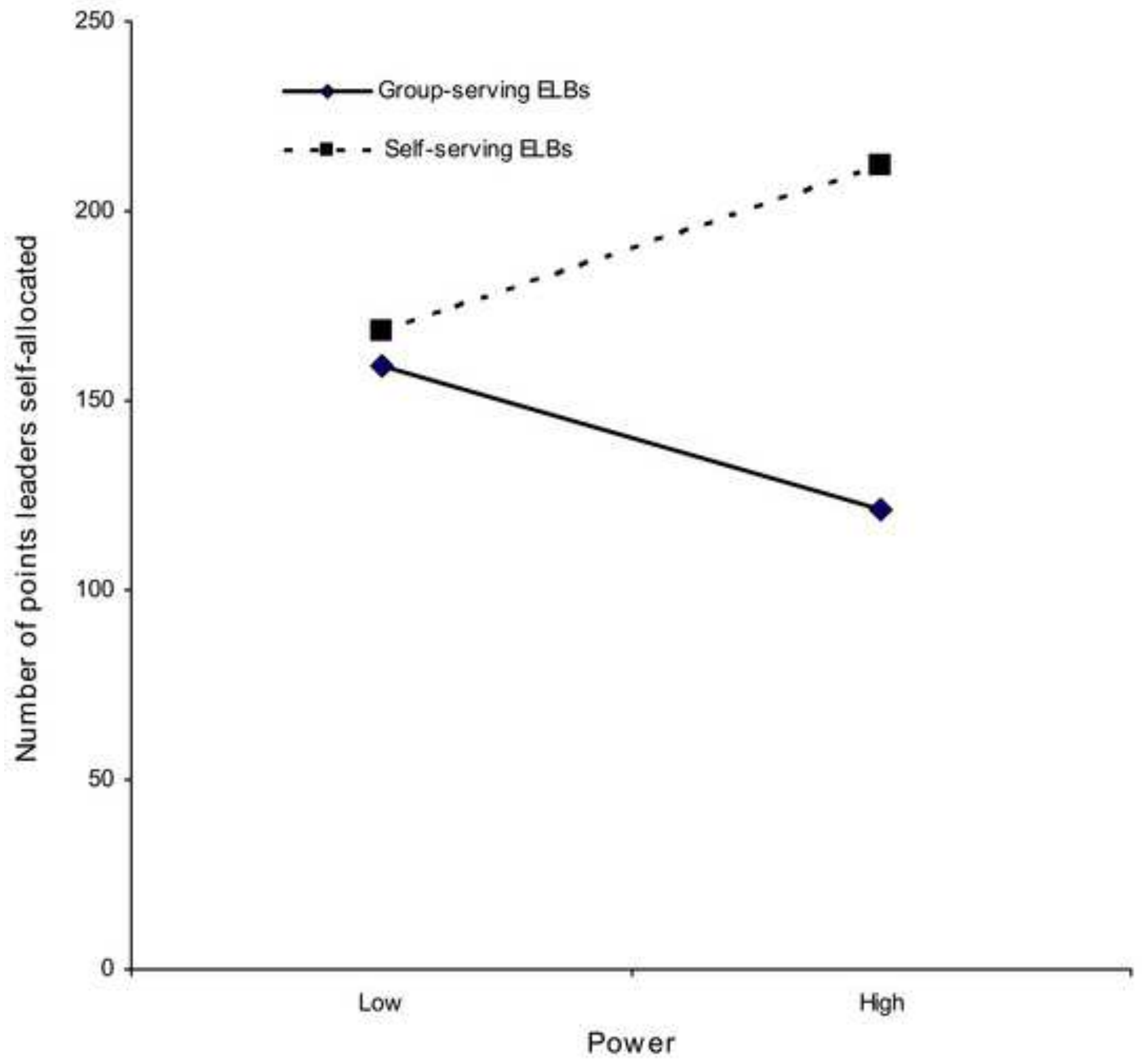


Figure 4

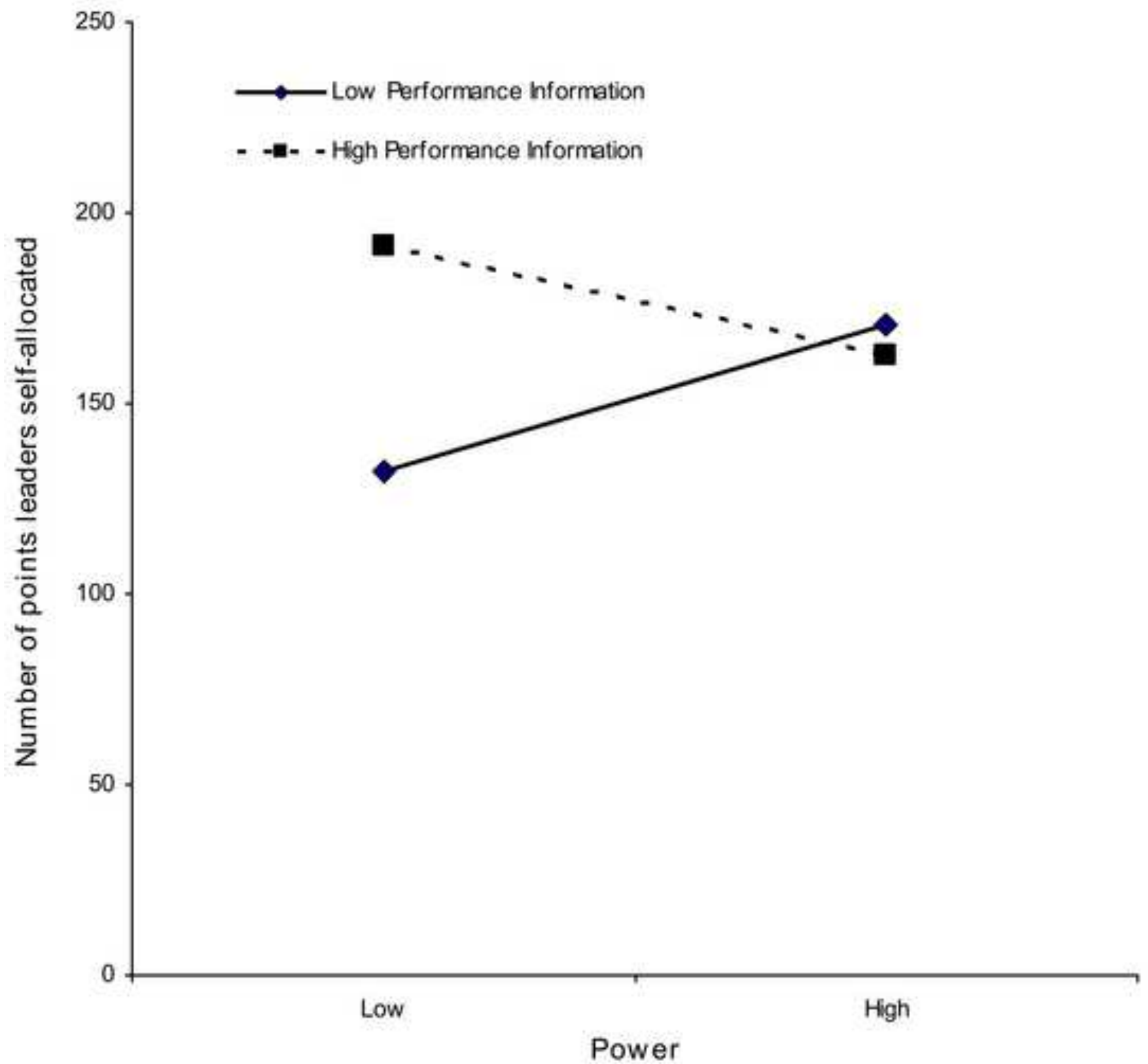


Figure 5

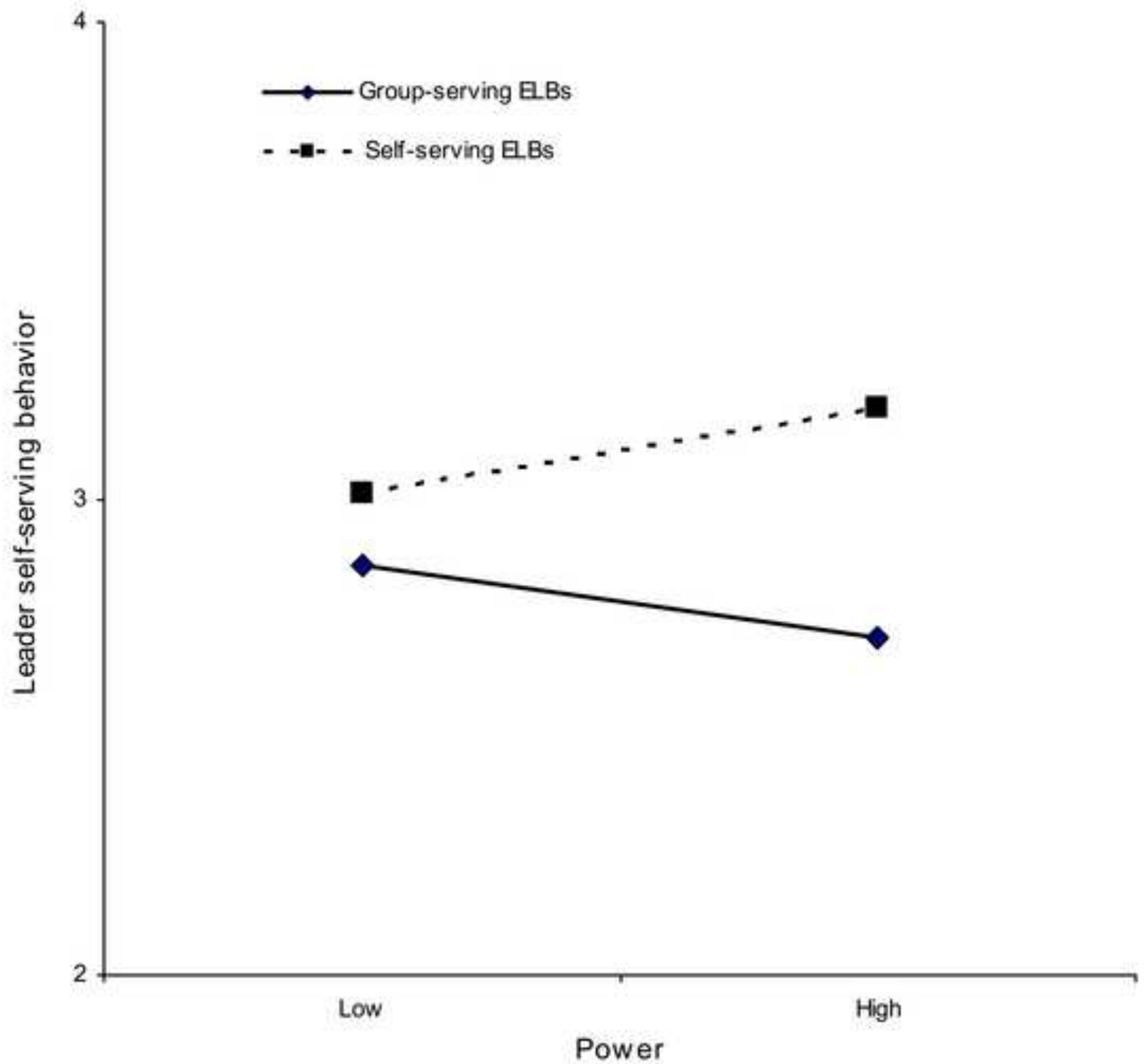


Figure 6

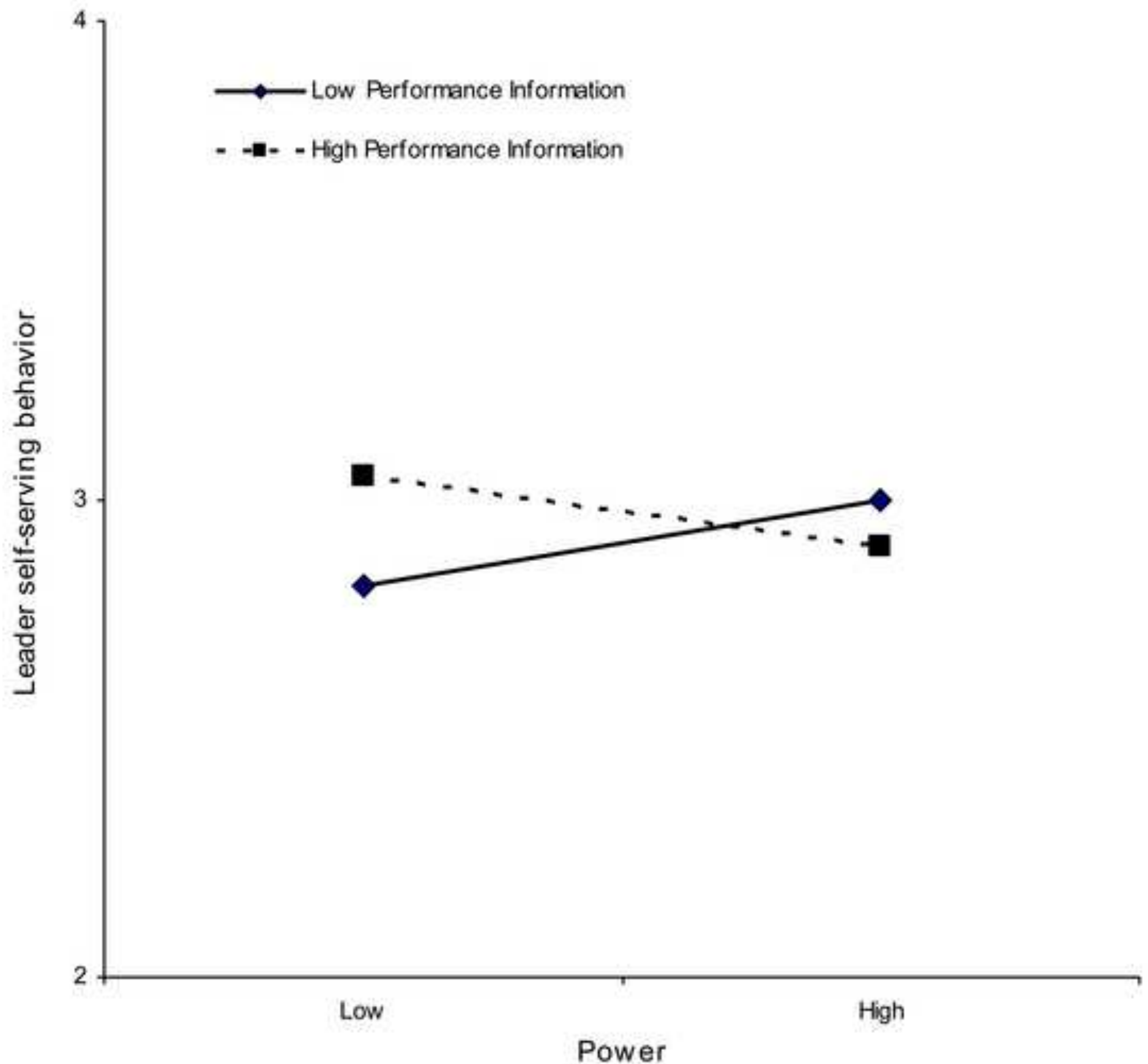

